\title{
Psycho-Educational Nursing Program for Enhancement the Quality of Life among Bladder Cancer Patients with Urinary Diversion
}

\section{Marwa Serag El Din Abd Elwaged ${ }^{1}$, Sayeda Ahmed Abd El latif ${ }^{2}$ and Rehab El Sayed Mohamed Ahmed ${ }^{3}$}

(1) Ph.D. Student of Psychiatric / Mental Health Nursing, Faculty of Nursing, Benha University, Egypt, (2) Professor of Psychiatric / Mental Health Nursing, Faculty of Nursing, Cairo University, Egypt and (3) Assistant professor of Psychiatric / Mental Health Nursing, Faculty of Nursing, Benha University, Egypt.

\begin{abstract}
Background: Developing psycho- educational nursing program has impact on the quality of life among bladder cancer patients with urinary diversion Aim of study: Was to determine the effect of psycho-educational nursing program for enhancement the quality of life among bladder cancer patients with urinary diversion. Research design: A quasi experimental design (pre and post - test) was used to achieve the aim of the study. Setting: This study was conducted at the Surgical Ward and Outpatient Clinics in National Cancer Institute, Cairo University. Sample: Purposive sample of 40 patients with urinary diversion from National Cancer Institute were selected from surgical ward. Tools of data collection: Two main tools were used, I: Structured interviewing questionnaire consisting of: Socio-demographic data and clinical data for patients. II: Pre-post assessment consisting of knowledge assessment questionnaire, Hamilton Anxiety Rating Scale and quality of life questionnaires. Results: There was a highly statistically significant improvement regarding to the total mean scores of Knowledge, quality of life and anxiety at post comparing to pre- program implementation. Conclusion: The findings of the study confirmed the effectiveness of psycho-educational nursing program for enhancement the quality of life among bladder cancer patients with urinary diversion. Recommendations: Providing patient with urinary diversion with needed support as well as an educational program will help them throughout respond in healthy to the urinary diversion.
\end{abstract}

Key words: Psycho- educational - Quality of life -Urinary diversion

\section{Introduction}

Globally, there are near half of million cases of bladder cancer discovered yearly. Bladder cancer is the fourth most common type of cancer in men and the eighth most common in women. Bladder tumors are four times more common in men than women, it accounts for $7 \%$ of cancers in men and $3 \%$ of cancers in women. The incidence of bladder cancer increases with age, it is rarely seen in people younger than 40 years of age and most commonly occurs in people between the age of 50 and 70 years (Ferlay et al., 2020).
Cancer patients considered as special group of patients due to psychological influence of the disease. The primary therapeutic modality for patients with bladder cancer is surgery in the form of radical cystectomy is still the best choice, followed by urinary diversion. After such surgery, male patients are left with two main problems namely impotence and the presence of a stoma, which have a devastating psychological impact on life. Patients with bladder cancer under urinary diversion surgery are at risk for developing psychological distress and ineffective 
Quality Of Life (QOL) after the urinary diversion surgery (Pashos et al., 2019).

Acute psychological distress is to be expected as a patient confronts the implications of illness, possible death, pain, dependence on others, disability, and disfiguring changes in the body (Vaihkonen et al., 2019). Among the psychological and physical stressors, "change in body image" is the most stressful factor affecting patients with bladder cancer, followed by hospitalization, social life, work factors, nature of illness and uncertainty stressors. Problem-oriented coping strategies were commonly used by the majority of the sample, followed by affective-oriented coping strategies (Helmy, 2018).

Patients with bladder cancer emotional functioning and Quality of Life will be affected by obviously the nature of the disease and its treatment strategies. QOL decreases following a bladder cancer diagnosis and continues for a prolonged period. So the intervention through implementing nursing Psycho - Educational nursing program might enhance QOL and minimize the hazards of the changes among bladder cancer Patients with urinary diversion is needed (Mariappan et al., 2016).

This study was performed to determine the effect of psycho- educational nursing program and assess its influence on QOL among urinary bladder cancer patients with urinary diversion.

\section{Significance of the study}

Bladder cancer is the fifth most common cancer; bladder cancer disease requires radical surgical treatment or chemo radiation with intensive surveillance that may negatively affect QOL. QOL for patients with bladder cancer has been limited. Urinary diversion is a serious operation which has an influence on QOL which include: Somatic, psychosocial, daylife activities and distress related to the body image (Bush and Butler, 2020). Intervention can focus on providing support and educational program to accept, respond and adapt to the diversion for bladder cancer patient.

\section{Aim of the study}

The aim of study was to assess the effect of psycho-educational nursing program and assess its impact on the quality of life among bladder cancer patients with urinary diversion.

\section{Research hypothesis}

Proposed Psycho - Educational nursing program would improve the quality of life among bladder cancer Patients with urinary diversion.

\section{Subjects and Method}

\section{Research Design:}

A quasi experimental design (pre and post - test) was used in this study.

\section{Research Setting:}

This study was conducted at the surgical ward and outpatient clinics in National Cancer Institute, Cairo University.

\section{Sample:}

Purposive sample of 40 patients diagnosed as bladder cancer with urinary diversion from National Cancer Institute were selected from surgical ward. This sample met the following criteria:

\section{Inclusion criteria:-}

1- Both sexes.

2- Age $>20$ years. 
3- Agreement of the patients for participation.

\section{Exclusion criteria:-}

1- Patients on chemotherapy or radiotherapy.

2- Patients have psychological, cognitive, and other disabling health problems.

3- Patients have another tumor.

\section{Tools of Data Collection:}

The data collected using two tools:

Tool (I): A structured Interview Questionnaire was developed by the researcher \& consisted of two parts:

Part I: Socio-demographic data: To elicit data about the patient's characteristics such as age, marital status.

Part II: Clinical data: Was included; duration of illness and duration of stay in hospital before surgery.

Tool (II): Pre-post assessment

\section{A. Knowledge assessment questionnaire:}

- Developed by the researcher to assess knowledge about urinary bladder, cystectomy, urinary diversion, caring of ostomy, and activities of daily living.

- Over all knowledge consist of 28 items scored from 0-28. Knowledge about urinary bladder ( 2 items) from 0-2, knowledge about cystectomy and urinary diversion (2 items) from $0-2$, knowledge about caring of ostomy (7 items) from 0-7 and knowledge about activities of daily living (17 items) from 0 17.

Scoring system of knowledge assessment questionnaire:

All knowledge consist of 28 items scored from $0-28$, where $0=$ wrong answer and $1=$ right answer.

1- 0- less than 17 indicated unsatisfied knowledge.

2- 17- 28 indicated satisfied knowledge.
B: Hamilton Anxiety Rating Scale (HAMA):

Developed by Hamilton (1959) the scale used to measure the severity of anxiety symptoms. Administration time for this tool is $10-15$ minutes. The scale consists of 14 items, each one defined by a series of symptoms, and measure both psychic anxiety (mental agitation and psychological distress) and somatic anxiety (physical complaints related to anxiety).

Scoring system of (HAM-A):

Each item was scored on a scale from 0 to 4 , where $0=$ not present, $1=$ mild, $2=$ moderate, $3=$ sever, and $4=$ very sever with a total score range of $0-56$, where:

1- 0-34 indicated mild severity of anxiety.

2- 35- 42 indicated moderate severity of anxiety.

3- 43-56 indicated sever severity of anxiety.

C: Quality of life Questionnaires FACTBl (Version 4): Developed by David Cella (1997) for patients with bladder cancer. Quality of life questionnaire (FACT-Bl) consists of subscales, physical well-being (7 items), social/family well-being (7 items), emotional well-being (6 items), functional well-being (7 items), and additional concerns (12 items).

Scoring system of Quality of life Questionnaires (FACT-BI (Version 4):

Each item is scored on a scale of 0 (not at all) to 4 (very much), with a total score range in physical well-being from $0-28$, social/family well-being from 0-28, emotional well-being from 0-24, functional well-being from 0-28, and additional concerns from 0-48, Where:

1- 0-78 indicated low QOL.

2- 79-116 indicated moderate QOL.

3- 117-156 indicated high QOL. 


\section{Tools validity and reliability}

A group of five experts made validity of tools. Two of them were specialized in the Psychiatric Medicine and the other three were specialized in the Psychiatric Nursing field to check the relevancy, clarity, comprehensiveness, and applicability of the questions. According to their opinions, modifications were done as, Modification of some words of Arabic form of the tool to give the right meaning of the phrase and the final form was developed. The dependability of the tools was evaluated by means of the Cronbach Alpha Coefficient test by evaluating their internal consistency. The tools proved to be strongly reliable. Reliability of first tool was 0.89 and the second tool was 0.92 .

\section{Pilot study:}

A pilot study was conducted on $10 \%$ of bladder cancer patients with urinary diversion equal 4 patients before embarking in the field of work to insure the clarity and applicability of the study tools also to identify the time needed for each patient interview. There was no modification carried out in any of the assessment tools so they included in the study.

\section{Ethical consideration:}

Before conducting the study the participants were assured about confidentiality and anonymity of their obtained information throughout the study. They were informed about their right to refuse to participate in the study and the right to withdraw from the study at any time.

\section{Field work:}

\section{Preparatory phase:}

This included reviewing of relevant literature of different studies related to the topic of research using textbooks, articles, and magazines to get clear pictures of all the aspects related to the research topic to design the program.

\section{Designing phase:-}

This phase aimed to designing for the psycho-educational nursing program through setting educational objectives, preparing the psycho-educational nursing program, designing the methodology and audio-visual aids was used.

\section{Development of psycho-educational nursing program}

The psycho-educational nursing program was developed by the researcher after a thorough review of the related literatures and after making the pilot study. The psycho-educational nursing program aimed to enhancement the quality of life among bladder cancer patients with urinary diversion. This program has a set of general objectives, and specific objectives for each session. The number of program's sessions was 8 sessions .3 sessions theoretical and 5 sessions practical. Based on the results obtained from the assessment tools and review of literature, the program content was developed by the researcher in the form of a booklet, which was revised and approved by the supervisors, after that the final booklet is distributed for bladder cancer patients with urinary diversion in the first session.

Session 1: Acquaintance, Introductory session, and pre-test.

Session 2: Overview about bladder function and dysfunction, urinary bladder cancer and urinary diversion.

Session 3: Information about the stoma and practical application to take care of it.

Session 4: Coping with stoma to enhancement quality of life.

Session 5: Coping with stoma to enhancement quality of life. 
Session 6: Developing relaxation techniques to overcome anxiety.

Session 7: Application of relaxation technique.

Session 8: Summery of the program sessions.

\section{Implementation Phase:-}

This phase was beginning by data collection then implementation of psychoeducational nursing program.

\section{Evaluation Phase (post-test).}

This phase aimed to estimate the effect of psycho-educational nursing program on enhancement the quality of life among bladder cancer patients with urinary diversion. Fill in post - test.

\section{Methods of evaluation:-}

Feedback through: oral questions, redemonstration, positive participation, direct observation, role play.

\section{Statistical analysis:}

The collected data were organized, computerized, tabulated and analyzed by using the Statistical Package for Social Science (SPSS) version 20. Data analysis was accomplished by the use of number, percentage distribution, mean, and standard deviation. Paired t-test was used to compare means within group, and t-test was used to compare two independent means. A significant level value was considered when p- value $=<0.05$.

\section{Limitation or Difficulties of the Study:}

- Patients were tired from operation.

- There was no special place for conducting the program, and difficulty of movement for some patients after the operation, hence, the researcher dealing with each case separately.

- Difficult in obtaining the approval of the Central Agency for Mobilization and Statistics.

- Coronavirus spread.

\section{Results:}

Table (1): Reveals that, $80 \%$ of the studied patients are male, $(87.5 \%)$ their age more than 50 years old, $82.5 \%$ are married, $50 \%$ of them not work, $(37.5 \%)$ are illiterate, and (52.5\%) are live in urban. 50\% of them duration of illness range from 7 months to 1 year. $32.5 \%$ of them stay in hospital 1 weak.

Table (2): Reveals that, there is a highly statistical significant improvement in all items of knowledge post psycho educational nursing program implementation than preprogram implementation at $(\mathrm{P}<0.001)$.

Table (3): Reveals that, there is a highly statistical significant improvement in the mean score of mean score of Total quality of life levels post psycho educational nursing program implementation than pre intervention program implementation at $(\mathrm{P}=$ $<0.001)$.

Figure (1): Shows that, (90\%) of the studied patients have mild anxiety post program implementation compare to $(25 \%)$ have mild anxiety preprogram implementation, and (10\%) of the studied patients have moderate anxiety post program implementation compare to $(75 \%)$ have moderate anxiety preprogram implementation.

Table (4): Illustrates that, there is a highly positive statistical significant correlation between studied patients total of level of anxiety and total levels of quality of life Post intervention of psycho-educational nursing program implementation. 
Psycho-Educational Nursing Program for Enhancement the Quality of Life among Bladder Cancer Patients with Urinary Diversion

Table (1): Number and percentage of the studied patients according to socio-demographic characteristics and clinical data of studied patients $(n=40)$

\begin{tabular}{|c|c|c|}
\hline & No. & $\%$ \\
\hline \multicolumn{3}{|l|}{ Socio-demographic data } \\
\hline \multicolumn{3}{|l|}{ Sex } \\
\hline Male & 32 & 80.0 \\
\hline Female & 8 & 20.0 \\
\hline \multicolumn{3}{|l|}{ Age } \\
\hline $20>50$ & 5 & 12.5 \\
\hline$>50$ & 35 & 87.5 \\
\hline \multicolumn{3}{|l|}{ Marital status } \\
\hline Married & 33 & 82.5 \\
\hline Divorced & 3 & 7.5 \\
\hline Widowed & 4 & 10.0 \\
\hline \multicolumn{3}{|l|}{ Occupation } \\
\hline Not working & 20 & 50.0 \\
\hline Free works & 15 & 37.5 \\
\hline Retired & 5 & 12.5 \\
\hline \multicolumn{3}{|l|}{ Education } \\
\hline Illiterate & 15 & 37.5 \\
\hline Read and write & 1 & 2.5 \\
\hline Primary school level & 1 & 2.5 \\
\hline Secondary school level & 12 & 30.0 \\
\hline University school level & 11 & 27.5 \\
\hline \multicolumn{3}{|l|}{ Residence } \\
\hline Urban & 21 & 52.5 \\
\hline Rural & 19 & 47.5 \\
\hline \multicolumn{3}{|l|}{ Clinical data } \\
\hline \multicolumn{3}{|l|}{ Duration of illness } \\
\hline $1-6$ months & 5 & 12.5 \\
\hline $7-12$ months & 20 & 50.0 \\
\hline $3-5$ years & 15 & 37.5 \\
\hline \multicolumn{3}{|c|}{ Duration of staying in hospital } \\
\hline$>1$ week & 7 & 17.5 \\
\hline 1week & 13 & 32.5 \\
\hline 2weeks & 10 & 25.0 \\
\hline More than 2 weeks & 10 & 25.0 \\
\hline
\end{tabular}


Table (2): Mean score of total knowledge about bladder cancer pre and post program implementation $(\mathbf{n}=\mathbf{4 0})$

\begin{tabular}{|l|c|c|c|c|}
\hline \multicolumn{1}{|c|}{ Items } & $\begin{array}{c}\text { Preprogram } \\
\text { implementation }\end{array}$ & $\begin{array}{c}\text { Post program } \\
\text { implementation }\end{array}$ & \multirow{2}{*}{ T } & \multirow{2}{*}{ P } \\
\cline { 2 - 5 } & Mean \pm SD. & Mean \pm SD. & & \\
\hline Knowledge about urinary bladder & $46.25 \pm 38.21$ & $93.75 \pm 16.75$ & 6.09 & $<0.001^{* *}$ \\
\hline $\begin{array}{l}\text { Knowledge about cystectomy and } \\
\text { urinary diversion }\end{array}$ & $28.75 \pm 25.03$ & $93.75 \pm 16.75$ & 17.71 & $<0.001^{* *}$ \\
\hline Knowledge about caring of the stoma & $28.57 \pm 12.53$ & $98.21 \pm 4.78$ & 32.84 & $<0.001^{* *}$ \\
\hline knowledge about daily living activity & $14.12 \pm 6.77$ & $81.47 \pm 16.56$ & 19.87 & $<0.001^{* *}$ \\
\hline Total knowledge & $\mathbf{2 1 . 0 7 \pm \mathbf { 8 . 4 4 }}$ & $\mathbf{8 7 . 4 1 \pm \mathbf { 1 2 . 3 2 }}$ & 29.23 & $<0.001^{* *}$ \\
\hline
\end{tabular}

Table (3): Mean score of total Quality of Life levels of the studied patients pre and post program implementation $(n=40)$

\begin{tabular}{||l|c|c|c|c||}
\hline \multirow{3}{*}{ Items } & $\begin{array}{c}\text { Preprogram } \\
\text { implementation }\end{array}$ & $\begin{array}{c}\text { Post program } \\
\text { implementation }\end{array}$ & \multirow{2}{*}{ T } & \multirow{2}{*}{ P } \\
\cline { 2 - 4 } & Mean \pm SD. & Mean \pm SD. & & \\
\hline Physical well-being & $19.46 \pm 25.54$ & $66.07 \pm 11.29$ & 15.93 & $<0.001^{* * *}$ \\
\hline Social/family well-being & $68.39 \pm 11.57$ & $77.68 \pm 8.81$ & 9.31 & $<0.001^{* *}$ \\
\hline Emotional well-being & $23.96 \pm 31.13$ & $71.04 \pm 10.38$ & 10.69 & $<0.001^{* *}$ \\
\hline Functional well-being & $22.59 \pm 24.96$ & $47.77 \pm 19.47$ & 10.69 & $<0.001^{* *}$ \\
\hline Additional concerns & $47.55 \pm 5.14$ & $64.27 \pm 6.70$ & 12.50 & $<0.001^{* *}$ \\
\hline Total Quality of Life levels & $38.14 \pm 15.30$ & $65.08 \pm 7.48$ & 18.26 & $<0.001^{* *}$ \\
\hline
\end{tabular}

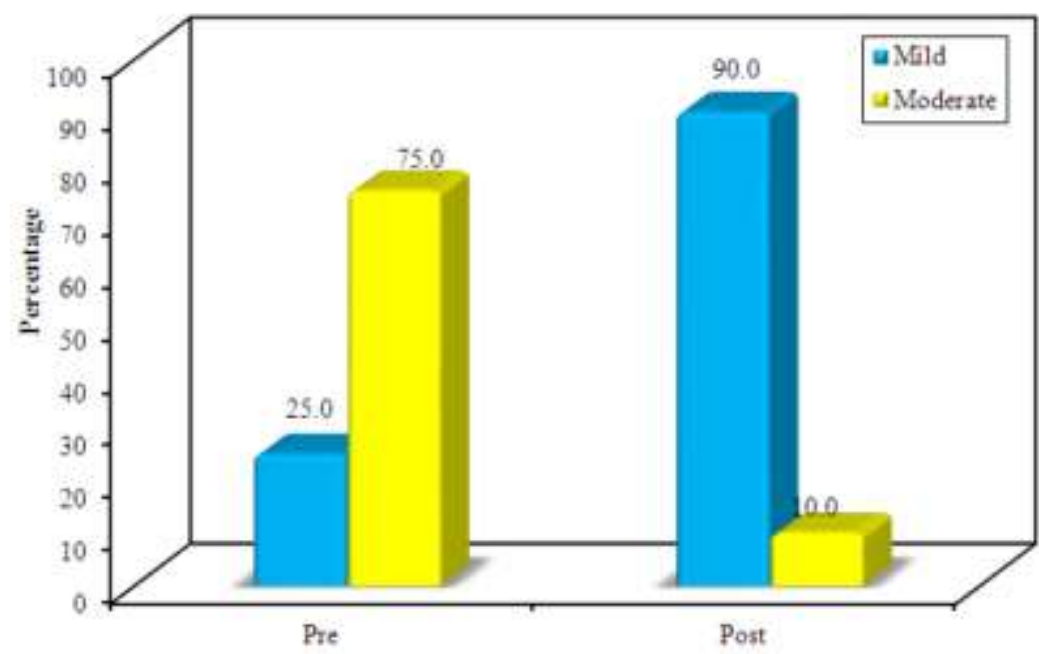

Figure (1): Comparison between pre and post program implementation of studied patient according to their levels of anxiety $(n=40)$ 
Table (4): Correlation between the studied patients their levels of anxiety, knowledge and quality of life pre and post program implementation $(n=40)$

\begin{tabular}{|l|c|c|c|c|}
\hline \multirow{2}{*}{ Items } & \multicolumn{2}{c|}{$\begin{array}{c}\text { Preprogram } \\
\text { implementation }\end{array}$} & \multicolumn{2}{c|}{$\begin{array}{c}\text { Post program } \\
\text { implementation }\end{array}$} \\
\cline { 2 - 5 } & $\mathbf{r}$ & $\mathbf{P}$ & $\mathbf{R}$ & \multicolumn{1}{|c|}{$\mathbf{P}$} \\
\hline Level of Anxiety vs. level of quality of Life & 0.542 & $<0.01^{* *}$ & -0.65 & $<0.01^{* *}$ \\
\hline Level of Anxiety vs. knowledge & -0.252 & 0.116 & 0.44 & $<0.01^{* *}$ \\
\hline Level of Quality of Life vs. knowledge & -0.909 & $<0.01^{* *}$ & -0.50 & $<0.01^{* *}$ \\
\hline
\end{tabular}

\section{Discussion}

Bladder cancer is the fifth most common cancer; bladder cancer disease requires radical surgical treatment or chemo radiation, intense treatment and surveillance may negatively affect QOL. QOL for patients with bladder cancer has been limited. Among patients with bladder cancer undergoing cystectomy, a limitation in the current understanding of QOL among patients with bladder cancer is how patients' QOL changes after diagnosis (Fattah and Moursy, 2019).

So, the current study aimed to assess the effect of psycho- educational nursing program and assess its impact on the quality of life among bladder cancer patients with urinary diversion

Regarding patients' gender, the current study demonstrated that, majority of the studied patients were male. This means that, males were more prone to be affected than females, may be due to the risk factors that cause bladder cancer like cigarette smoking which is known to increase the risk of developing transitional cell carcinoma in smokers by much as four times that in nonsmokers. Women, in Egyptian culture generally do not smoke cigarettes with the same frequency as do men. Also, industrial exposure to known carcinogens constitutes a significant risk factor. Those people at greatest risk include; textile workers, painters, hair-dressers, leather, metal workers and rubber industries, men usually occupy these types of work, which may explain why men are four times more likely to develop the disease than females.

This result was in agreement with (Rammant et al., 2020) who conducted a study entitled "Health-related quality of life overview after different curative treatment options in muscle-invasive bladder cancer" and found that majority of patients were male,

Regarding patients' age, the current study demonstrated that, majority of the studied patients had age more than 50 years old. This means that the older the patients, the higher the incidence of bladder cancer. This result may be due to the predisposing factors of the disease were accumulated by the time and with the advancement of the age. This result was in agreement with (Pham et al., 2019) who conducted a study entitled "Mental health implications in bladder cancer patients" and found that majority of patients had ages more than 50 years.

Regarding patients ' marital status, the current study demonstrated that, majority of the studied patients were married. This result may be due to the disease mostly 
affecting older patients and majority of them were married. This result was in agreement with (Rammant et al., 2020) who conducted a study entitled "Health-related quality of life overview after different curative treatment options in muscleinvasive bladder cancer" and found that majority of patients were married.

Regarding patients ' education level, the current study demonstrates that, more than one third of the studied patients were illiterate. From the researcher point of view this result may be indicated the great effect of education in prevention of bladder cancer. Conversely, this result was in disagreement with (Pham et al., 2019) who conducted a study entitled "Mental health implications in bladder cancer patients" and found that more than half of them were read and write.

Regarding patient's pre and post program implementation according to their total knowledge, the current study revealed that, there was a highly statistical significant improvement in all items of knowledge post psycho educational nursing program implementation than preprogram implementation. From the researcher point of view, this result may be due to training program affect patients' knowledge positively that appeared in the highest scores in the post intervention phase. The studied patients were prone to the educational program which covered all the knowledge, and skills needed by the patient based on the assessment done during the pilot study and included all items related to the knowledge about urinary diversion surgery and how to adapt to the stoma.

This result was supported with (Shi et al., 2020) who conducted a study entitled "Effect of educational intervention and telephone follow-up program on knowledge, practice and quality of life among patients with urinary diversion" and found that there was a highly statistical significant improvement in all items of the knowledge about urinary bladder post implementation educational nursing program. Additionally, this result was in agreement with (Zhou et al., 2019) who conducted a study entitled "Effect of ostomy care team intervention on patients with ileal conduit" and found that there was a statistical significant improvement in items of the knowledge about ostomy care post implementation educational nursing program.

Regarding patient's pre and post program implementation according to their quality of life levels, the current study revealed that, there was a highly statistical significant improvement in the mean score of all items of quality of life levels post psycho educational nursing program implementation than pre intervention program implementation. A possible explanation of the this finding was that in order to maintain the highest quality of life, once cancer had developed, patients need new knowledge and skills for self-care. The studied patients received intensive information about how they can live with the stoma as if it is not present, so, it was expected that their quality of life change to the better.

This result was accordance with (Shi et al., 2020) who conducted a study entitled "Effect of Orem's self-care model on quality of life and complications in the patients with cutaneous ureterostomy after radical cystectomy" and found that there was a highly statistical significant improvement of quality of life after implementation educational nursing program. Also, this 
result was in agreement with (Moghalu et al., 2021) who conducted a study entitled "Psychosocial aspects of health-related quality of life and the association with patient-reported bladder cancer" and found that there was a statistical significant improvement of quality of life after implementation educational nursing program.

Also, this result was in agreement with (Rammant et al., 2020) who conducted a study entitled "Health-related quality of life overview after different curative treatment options in muscleinvasive bladder cancer" and found that there was a highly statistical significant improvement of quality of life after implementation training program. Also, this result was in agreement with (Miller et al., 2020) who conducted a study entitled "Development of a remote monitoring application to improve care and support patients in the first 30 days following Bladder cancer" and found that there was a highly statistical significant improvement of quality of life after implementation training program.

Regarding patients pre and post program implementation according to levels of anxiety, the current study demonstrated that, there was a marked improvement in the mean score of all items of anxiety level post intervention than pre intervention with statistical significance difference between pre and post implementation of psychoeducational nursing program.

Possible explanation for this finding was that patients with cancer seem to experience psychological and relational problems due to many concerns that involve uncertainty about the deterioration of their health, future prospects, confrontation with death and fear of the dying process. The patients found opportunities to discuss their fears, concerns, and ask all questions they search for meanings, during the educational and supportive group, carried out by the researcher with the help of a physician specialist in group therapy. Through informing patients, assessing their problems, giving them emotional support, their psychological state was getting better than before implementation of the program. This does not means that everything was ok but at least the patients became less distressed.

The current study Illustrate that, there was a highly positive significant correlation between studied patients total of anxiety and total of quality of life Post intervention of psycho-educational nursing program implementation. From the researcher point of view, this result may be due to high level of knowledge affecting the quality of life of the patients and affective state is negatively correlated to quality of life. This means that while the anxiety was decrease, the quality of life was improved.

This result was supported with (Almanzalawy, 2020) who conducted a study entitled "Effect of Self-Management Program on the Patient 'Knowledge and Practice Regarding Stoma Care" and found that there was a highly positive significant correlation between patients total of 'Knowledge and Practice Post intervention of educational nursing program. Also, this result is in agreement with (Hubbard et al., 2020) who conducted a study entitled " A physical activity intervention to improve the quality of life of patients with a stoma " and found that there was a highly positive significant correlation between studied 
patient's total of quality of life Post intervention of educational nursing program.

\section{Conclusion}

Based on the results of the present study, the findings confirmed the effectiveness of psycho-educational nursing program for enhancement the quality of life among bladder cancer patients with urinary diversion receiving psycho-educational nursing program. There was highly statistically significant correlation between studied patients total of anxiety and total of quality of life Post intervention of psychoeducational nursing program implementation. This conclusion leads to the acceptance of the study hypothesis that improves the Quality of Life among bladder cancer Patients with urinary diversion after implementation of psycho-educational nursing program.

\section{Recommendations}

1- The care givers they should be equipped with knowledge, has experience and develop their personal skills to be able to enhance the improving the quality of care (QOL) of patients with bladder cancer

2- Multidisciplinary team protocol of care should be implemented to reach patient holistic care.

3- Continuing-educational programs for nurses that emphasize the patient's need for physical, psychological, social and spiritual support .

4- Self-instruction manual and /or Video about the care of the stoma, types of food, types of activities and adaptation strategies after urinary diversion surgery should be available in any surgical ward.

5- Communicate the study results with the health authority for integrating the program for patients with bladder cancer

\section{References:}

Almanzalawy, H. (2020). Effect of SelfManagement Program on the Patient'Knowledge and Practice Regarding Stoma Care. Assiut Scientific Nursing Journal, 8(23.00), 55-66.

Bush, N., \& Butler, L. (2020). Quality of life and the cancer experience: the state-ofthe-knowledge. Oncology Nursing Forum, 24 (1), 27-41.

David Cella, (1997). The Functional Assessment of Cancer Therapy Scale: development and validation of the general measure. J Clin Oncol;11: 570-79.

Fattah, M., \& Moursy, A. (2019). Quality of life among patients living with stoma. Assiut Scientific Nursing Journal, 8(22), 217-225.

Ferlay J., Soerjomataram I., Dikshit R., Eser S., Mathers C., \&Rebelo M., (2020). Cancer incidence and mortality worldwide: sources, methods and major patterns in GLOBOCAN 2020. Int J Cancer;136: E359-E386.

Hamilton M. (1959). The assessment of anxiety states by rating. Br J Med psychol 1959;32:50-55.

Helmy, N. (2018). Identification of stressors and coping strategies among patients with bladder cancer. Unpublished master thesis, Faculty of Nursing, Cairo University, p. 132.

Hubbard, G., Taylor, C., Watson, A., \&Munro, J., (2020). A physical activity intervention to improve the quality of life of patients with a stoma: a feasibility study. Pilot and feasibility studies, 6(1), 1-15.

Mariappan, P., Finney, S., Head, E., Somani, B., Zachou, A., Smith, G., \& Grigor, K., (2016). Good quality white-light transurethral resection of bladder tumours 
(GQ-WLTURBT) validation across time and place and recommendation for benchmarking. BJU international, 109(11), 1666-1673.

Miller, M., Roxburgh, C. S., McCann, L., Connaghan, J., \& Maguire, R. (2020). Development of a remote monitoring application to improve care and support patients in the first 30 days following Bladder cancer. In Seminars in Oncology Nursing (p. 151086). WB Saunders.

Moghalu, O., Stoffel, J. T., Elliott, S., \&Welk, B., (2021). Psychosocial aspects of health-related quality of life and the association with patient-reported bladder cancer. Bladder cancer, 1-10

Pashos, C., Botteman, M., Laskin, B., \& Redaelli, A. (2019). Bladder cancer: epidemiology, diagnosis, and management. Cancer practice, 10(6), 311-322.

Pham, H., Torres, H., \& Sharma, P. (2019). Mental health implications in bladder cancer patients: a review. In Urologic Oncology: Seminars and Original Investigations (Vol. 37, No. 2, pp. 97-107).

Rammant, E., Van Wilder, L., Van Hemelrijck, M., \& Fonteyne, V. (2020). Health-related quality of life overview after different curative treatment options in muscleinvasive bladder cancer: an umbrella review. Quality of Life Research, 29, 2887-2910.

Shi, Y., Gu, Z., Yuan, H., Yang, J., \& Xia, J. (2020). Effect of Orem's self-care model on quality of life and complications in the patients with cutaneous ureterostomy after radical cystectomy. KUWAIT MEDICAL JOURNAL, 52(1), 23-28.

Vaihkonen, K., Achte, R., Lehyonen, M., and Holti, L. (2019). Psychological aspects of breast cancer treatment. Journal of Advanced Nursing, 23, 165-170.
Zhou, H., Ye, Y., Qu, H., Zhou, H., Gu, S., \& Wang, T. (2019). Effect of ostomy care team intervention on patients with ileal conduit. Journal of Wound Ostomy \& Continence Nursing, 46(5), 413-417. 


\section{برنامج تمريضي نفسي تعليمي لتحسين جودة الحياة عند مرضي سرطان المثانه الخاضعين لتحويل البول}

$$
\text { مروة سر اج الدين عبد الو اجد - سيدة احمد عبد اللطيف ـ رحاب السيد محمد احمد }
$$

إن لسرطان المثانة ضغوط نفسية وجسدية.ويعتبر "التغيير في جودة الحياة" هو العامل الأكثر إرهاقًا الذي يؤثر على المرضى ، يليه الحياة الاجتماعية ، وعوامل العمل ، وطبيعة المرض. في الوقت نفسه ، قد

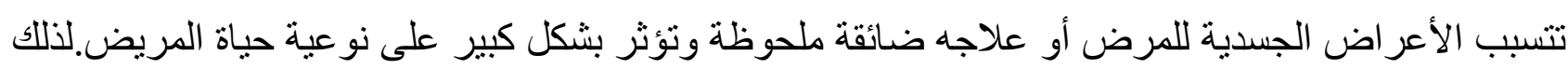

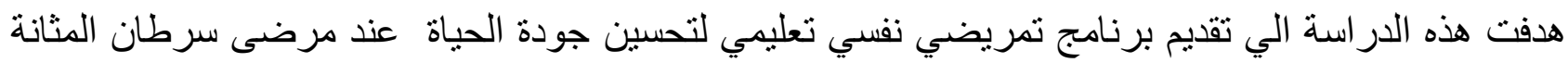
الخاضعين لتحويل البول. وقد اجريت هذه الدراسة في المعهد القومي للاور ام بجامعة القاهرة وقد شملت عينة

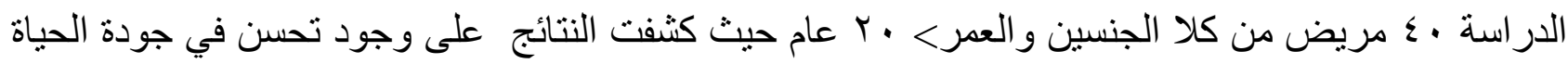

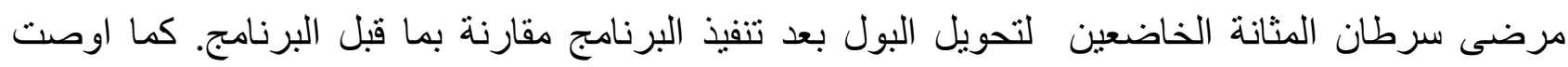

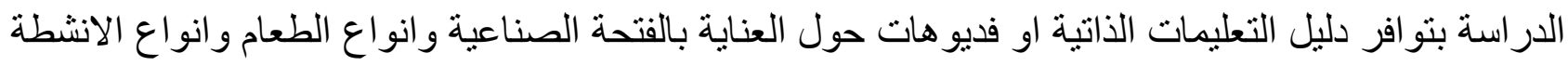

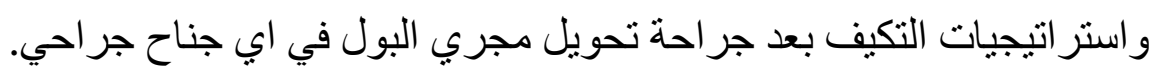

